\title{
Myocardial GLP-1 Receptor Activation in the Presence of Glucose: Strong Partners
}

\author{
Ewald Kolesnik ${ }^{1}$ - Thomas Krainer $^{1} \cdot$ Markus Wallner $^{1,2} \cdot$ Natasa Djalinac $^{1} \cdot$ Nicolas Verheyen $^{1} \cdot$ Klemens Ablasser $^{1}$. \\ Deborah M. Eaton ${ }^{2} \cdot$ Peter P. Rainer $^{1} \cdot$ Brigitte Pelzmann $^{3}$. Dirk von Lewinski ${ }^{1}$
}

Accepted: 11 April 2018 / Published online: 18 April 2018

(c) The Author(s) 2018

\begin{abstract}
Glucagon-like peptide 1 (GLP-1) receptor agonists increase the intracellular calcium levels of atrial cardiomyocytes in a protein kinase A dependent manner. This elicits a positive inotropic effect. Furthermore, the translocation of GLUT1 is promoted. The relevance of the latter process is unclear, therefore we assessed the influence of energy substrates. Muscle strips (trabeculae; $\mathrm{n}=86$ ) were isolated from human right atrial appendages obtained from patients undergoing heart surgery $(\mathrm{n}=34)$, mounted on hooks, electrically stimulated $(1 \mathrm{~Hz})$ and treated with a single dose of exenatide (15 nM), GLP-1(7-36) amide (180 nM), GLP-1(9-36) amide (200 nM), isoproterenol (100 nM), or increasing concentrations of calcium (4.0 and $7.2 \mathrm{mM}$ ). Either $11.2 \mathrm{mM}$ glucose or $22.4 \mathrm{mM}$ pyruvate served as the energy substrate. Developed force, diastolic tension and relaxation parameters were recorded and analyzed. Administration of exenatide and GLP-1(7-36) amide, but not GLP1(9-36) amide, led to a transient positive inotropic effect in the presence of pyruvate and glucose. This effect tended to be more pronounced in glucose-treated muscle strips at maximal developed force and steady state conditions. Both isoproterenol and calcium exerted a strong positive inotropic effect with no difference regarding the energy substrate. In conclusion, the positive inotropic effect of GLP-1 receptor agonists is more pronounced in glucose enriched Tyrode's solution, which might be linked to the previously reported translocation of GLUT1.
\end{abstract}

Keywords Glucagon-like peptide 1 - Incretin mimetics · Anti-diabetic drugs · Atrial contractility · GLUT1

\section{Abbreviations}

ATP Adenosine-3-phosphate

BL Baseline, optimally stretched muscle strip where maximum developed force is generated

Ewald Kolesnik and Thomas Krainer have contributed equally to this work.
2,3-BDM 2,3-Butanedione monoxime

GLP-1 Glucagon-like peptide 1

GLUT Glucose transporter

SSC Steady state conditions (usually 25 min after intervention)

T2DM Type-2 diabetes mellitus

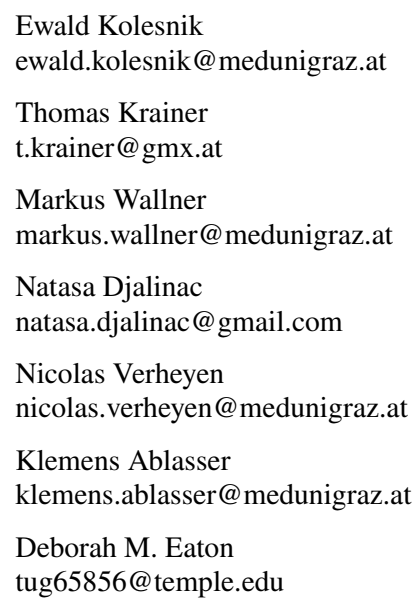

Peter P. Rainer peter.rainer@medunigraz.at

Brigitte Pelzmann

brigitte.pelzmann@medunigraz.at

Dirk von Lewinski

dirk.von-lewinski@medunigraz.at

1 Department of Cardiology, Medical University of Graz, Auenbruggerplatz 15, 8036 Graz, Austria

2 Cardiovascular Research Center, Temple University Lewis Katz School of Medicine, Philadelphia, PA, USA

3 Institute of Biophysics, Medical University of Graz, Graz, Austria 


\section{Introduction}

Type-2 diabetes mellitus (T2DM) is a major cardiovascular risk factor. The impaired glucose metabolism leads to elevated blood sugar levels and damages both large and small blood vessels. Therefore, severe cardiovascular diseases such as myocardial infarction, ischemic heart failure, or stroke may result (Nolan et al. 2011; Vaidya et al. 2015). The primary goal for treating diabetes is to both regulate and reduce glucose levels. A second major treatment goal is to reduce cardiovascular complications (Standl et al. 2016; Bailey et al. 2013; Strang et al. 2015). There are many different treatment options available, ranging from simple diet changes to the use of combination therapy with multiple pharmacological agents (Qaseem et al. 2017). Many anti-diabetic drugs, especially when used in combination with other anti-diabetic drugs or prescribed to patients with renal failure, can induce hypoglycemic conditions that represent a dangerous side effect (Tschope et al. 2016; Bruderer et al. 2014) and a risk factor for mortality or severe cardiovascular complications such as heart failure (Zoungas et al. 2010). Glucagonlike peptide 1 (GLP-1) receptor agonists constitute a new therapeutic approach for the treatment of T2DM (Drucker and Nauck 2006). The anti-diabetic effect is caused by an augmentation of the glucose dependent insulin secretion from pancreatic beta cells via the GLP-1 receptor, which is referred to as the incretin-effect (Baggio and Drucker 2007). This mechanism prevents potential harmful hypoglycemic conditions.

Besides pancreatic beta cells, the GLP-1 receptor is also expressed on the surface of cardiomyocytes. Previous studies demonstrated that expression levels are much higher in human atrial cells than in ventricular cells (Richards et al. 2014; Wallner et al. 2015). GLP-1 receptor activation leads to an increase of intracellular calcium levels in a protein kinase A dependent manner causing a transient positive inotropic effect. Furthermore, translocation of glucose transporter (GLUT) 1 and exchange proteins activated by cAMP (Epac2) is promoted in atrial cardiomyocytes (Wallner et al. 2015).

In light of previous studies that elucidated the positive inotropic effect, we assessed the role of energy substrates on the functional aspect.

\section{Materials and Methods}

This study was approved by the local ethics committee (Ethics Committee at Med Uni Graz: 19-109 ex 07/08) and all patients gave informed written consent according to the WMA Declaration of Helsinki, 2013. All experiments were performed using muscle strips (trabeculae) isolated from human right atrial appendages that were obtained from patients undergoing heart surgery $(n=34)$.

\section{Patient's Medical History}

Patients underwent coronary artery bypass graft (50\%), aortic valve replacement (15\%), or a combination of both procedures $(29 \%)$. One patient underwent mitral valve surgery $(3 \%)$ and another patient had combined mitral valve and aortic valve surgery (3\%). The mean age of all patients was $66 \pm 11$ years and $29 \%$ were female. Arterial hypertension was present in $88 \%$ of the patients, $24 \%$ were type- 2 diabetics, $12 \%$ of the patients had paroxysmal atrial fibrillation and $76 \%$ of the patients had a preserved left ventricular ejection fraction measured before surgery (mean ejection fraction $=54 \pm 10 \%$ ). The mean body mass index was $29 \pm 6 \mathrm{~kg} /$ $\mathrm{m}^{2}$. The right atrial appendage was cut off shortly after activation of the cardiopulmonary bypass pump.

\section{Muscle Strip Preparation and Experimental Setup}

Muscle strips (trabeculae) were isolated from human right atrial appendages in a cardioprotective Tyrode's solution containing $0.03 \mathrm{M}$ 2,3-Butanedione monoxime (2,3BDM). For the experiment, the trabeculae were fixed on hooks, superfused with modified Tyrode's solution (2,3$\mathrm{BDM}$ rinsed out) with a calcium concentration of $0.2 \mathrm{mM}$ and electrically stimulated at a frequency of $1 \mathrm{~Hz}$. Either $11.2 \mathrm{mM}$ glucose or $22.4 \mathrm{mM}$ pyruvate served as the energy substrate. All solutions used were constantly bubbled with 95\% oxygen and 5\% carbon dioxide. The calcium concentrations were elevated stepwise from 0.2 to $2.5 \mathrm{mM}$, and maximum preload was simulated by stretching the electrically stimulated trabeculae to an optimal length, which is defined as the maximum developed force at baseline (BL).

\section{Experimental Protocol and Data Analysis}

A single dose of exenatide $(15 \mathrm{nM})$ was added to 12 trabeculae isolated from 9 hearts (substrate: glucose) and 11 trabeculae isolated from 7 hearts (substrate: pyruvate). GLP 1(7-36) amide (180 nM) was added to 13 trabeculae isolated from 10 hearts (substrate: glucose) and 13 trabeculae isolated from 10 hearts (substrate: pyruvate). GLP1(9-36) amide (200 $\mathrm{nM}$ ) was added to 6 trabeculae isolated from 5 hearts (substrate: glucose) and 6 trabeculae isolated from 5 hearts (substrate: pyruvate). Isoproterenol $(100 \mathrm{nM})$ was added to 6 trabeculae isolated from 4 hearts (substrate: glucose) and 6 trabeculae isolated from 3 hearts (substrate: pyruvate). Another 6 trabeculae isolated from 4 hearts (substrate: glucose) and 7 trabeculae isolated from 
5 hearts (substrate: pyruvate) were treated with increasing concentrations of calcium ( 4.0 and $7.2 \mathrm{mM}$ ) to assess the inotropic response of the muscle strips without activation of downstream mechanisms that influence calcium regulating enzymes in cardiomyocytes. All chosen concentrations of GLP-1 receptor agonists and isoproterenol were based on previous data from dose-response experiments and selected in order to achieve maximal positive inotropic effects (Wallner et al. 2015; Lewinski et al. 2007). Developed force and diastolic tension were recorded and analyzed at BL, which is the time point of developed force maximum, and again at steady state conditions ( $=25 \mathrm{~min}$ after the intervention). Trabeculae that developed arrhythmic events were excluded from analysis. None of the patients had been treated with a GLP-1 receptor agonist. In the experiments using isoproterenol, patients who had been treated with beta blockers were excluded. Data are presented as relative values in (\%) of BL of muscle strips that were treated identically. The differences in developed force at steady state conditions are presented as the change in the relative values (delta of developed force) in (\%) of BL. Data are expressed as mean \pm SEM in all figures.

\section{Drugs and Substances}

Exenatide, GLP-1(7-36) amide and GLP-1(9-36) amide were purchased from Tocris (Bristol, United Kingdom). Glucose was purchased from Merck (Darmstadt, Germany). All other substances used were purchased from Sigma-Aldrich (Taufkirchen, Germany). The Tyrode's solution is made using $152 \mathrm{mM} \mathrm{Na}^{+}, 3.6 \mathrm{mM} \mathrm{K}^{+}, 0.6 \mathrm{mM} \mathrm{Mg}^{2+}, 0.2 \mathrm{mM}$ $\mathrm{Ca}^{2+}, 129.5 \mathrm{mM} \mathrm{Cl}^{-}, 25 \mathrm{mM} \mathrm{HCO}_{3}^{-}, 1.3 \mathrm{mM} \mathrm{H}_{2} \mathrm{PO}_{4}^{-}$, $0.6 \mathrm{mM} \mathrm{SO}_{4}{ }^{2-}, 5$ I.U. insulin and either $11.2 \mathrm{mM}$ glucose or $22.4 \mathrm{mM}$ pyruvate.

Exenatide is a synthetic polypeptide containing 39 amino acids, while GLP-1(7-36) amide is an intrinsic peptide containing 30 amino acids. GLP-1(7-36) amide is degraded rapidly by the enzyme dipeptidyl peptidase 4 (DPP4) under physiological conditions, but exenatide is resistant to degradation. The cleaved product of GLP-1(7-36) amide is GLP-1(9-36) amide, which contains only 28 amino acids and acts as an antagonist of the GLP-1 receptor. The function of GLP-1(9-36) amide is in contrast to the role of both exenatide and GLP-1(7-36) amide, that act as agonists of the GLP-1 receptor (Baggio and Drucker 2007). Isoproterenol is a beta receptor agonist and was used to compare possible differences of a positive inotropic effect when different energy substrates are used.

\section{Statistics}

Differences between factors (between and within factors) were tested by using a two-way ANOVA for repeated measures with Sidak's multiple comparison post hoc test.
To compare groups at one-time point, Student's unpaired $t$ test was used. Normal distribution was tested by using the Shapiro-Wilk-test. In case the assumption of normality was violated, a non-parametric equivalent was used instead. Data are expressed as mean \pm SEM. Values of $p<0.05$ were considered statistically significant.

\section{Results}

\section{The Inotropic Effect of Exenatide}

Administration of a single dose of $15 \mathrm{nM}$ exenatide led to a transient positive inotropic effect in the presence of pyruvate and glucose. Irrespective of the energy substrate, after exenatide administration the human atrial myocardium showed a strong increase in developed force within minutes followed by a decline to stable steady state conditions that were reached after $25 \mathrm{~min}$. As shown in Fig. 1a, the positive inotropic effect tends to be more pronounced in glucose treated muscle strips compared to pyruvate-treated muscle strips $(\mathrm{p}=0.055)$ at the time of maximum developed force $(194.1 \pm 27.0 \%$ in glucose versus $141.2 \pm 10.5 \%$ in pyruvate $)$ and at steady state conditions after $25 \mathrm{~min}(156.5 \pm 15.7 \%$ in glucose versus $116.1 \pm 5.1 \%$ in pyruvate). Figure $1 \mathrm{~b}$ shows the change in developed force between BL and steady state conditions after $25 \mathrm{~min}$. In glucose-treated muscle strips, the increase in developed force was significantly higher $(56.5 \pm 15.7 \%)$ compared to pyruvate treated muscle strips $(16.1 \pm 5.1 \%, p=0.03)$. Interestingly, there were some nonresponding muscle strips that did not show any change in developed force besides physiological rundown (33\% of the glucose-treated muscle strips and $18 \%$ of the pyruvatetreated muscle strips). Within the non-responding muscle strips, there were no obvious similarities in the patients' medical records such as diabetes, comorbidities or medications. Diastolic tension and relaxation parameters were not affected by exenatide (data not shown).

\section{The Inotropic Effect of GLP-1(7-36) Amide}

A single dose of $180 \mathrm{nM}$ GLP 1(7-36) amide revealed similar effects on developed force as seen after exenatide treatment. Figure 2a shows a rapid increase in developed force that occurred within a few minutes in the presence of glucose and pyruvate $(198.6 \pm 34.6 \%$ in glucose versus $110.0 \pm 4.4 \%$ in pyruvate; $p=0.0007$.) This effect was followed by a decrease in developed force to steady state conditions after $25 \mathrm{~min}(138.7 \pm 18.8 \%$ in glucose versus $99.9 \pm 3.3 \%$ in pyruvate; $p=0.25$ ). The increase in developed force at steady state was higher in muscle strips superfused with glucose-enriched solution $(38.7 \pm 18.8 \%)$ compared to pyruvate-enriched solution $(-0.1 \pm 3.3 \%, \mathrm{p}=0.052)$, with 

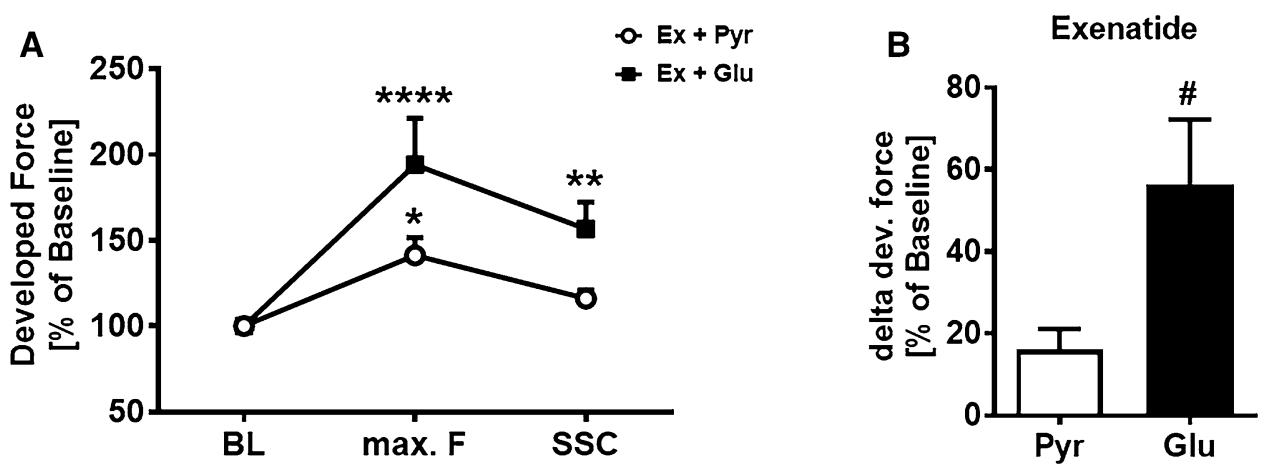

Fig. 1 Substrate-dependent inotropic effect of exenatide on human atrial myocardium. Exenatide exerts a positive inotropic effect in the presence of both substrates. There was a stronger effect in the presence of glucose. Data are represented as mean \pm SEM. BL: developed force baseline; max. F: maximal developed force; SSC: steady state conditions $25 \mathrm{~min}$ after intervention. a A single dose of $15 \mathrm{nM}$ exenatide was administrated on either glucose-treated (filled squares; $n=12$ trabeculae) or pyruvate-treated (open circles; $n=11$ trabeculae) trabeculae. Effect on developed force (glucose/pyruvate); $* \mathrm{p}<0.05$, $* * \mathrm{p}<0.01, * * * * \mathrm{p}<0.0001$ vs BL. No statistical difference between groups $(p=0.055)$. $\mathbf{b}$ Analysis of developed force delta to baseline at time point of steady state conditions for glucose-treated (black bar) and pyruvate-treated (white bar) muscle strips. ${ }^{\#} \mathrm{p}<0.05$ between groups
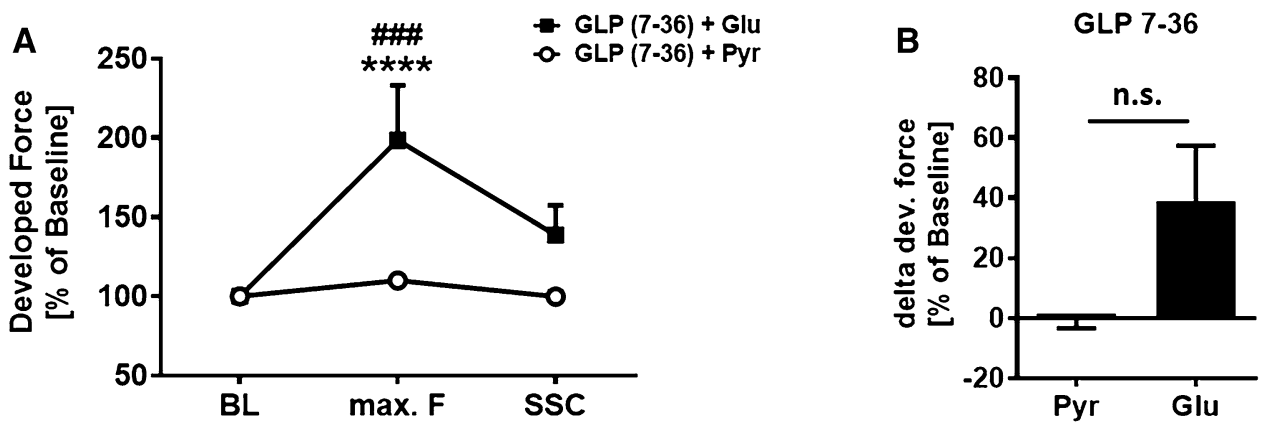

Fig. 2 Substrate-dependent inotropic effect of GLP-1(7-36) amide on human atrial myocardium. GLP-1(7-36) amide exerts a positive inotropic effect in the presence of both substrates. The effect tends to be stronger in the presence of glucose. Data are represented as mean \pm SEM. BL: developed force baseline; max. F: maximal developed force; SSC: steady state conditions $25 \mathrm{~min}$ after intervention. a A single dose of $180 \mathrm{nM}$ GLP-1(7-36) amide was administrated on

a borderline significant difference (Fig. 2b). Interestingly, following GLP-1(7-36) amide administration, a significant portion of muscle strips did not respond with a positive inotropic effect ( $31 \%$ of the glucose-treated muscle strips and $54 \%$ of the pyruvate-treated muscle strips). No changes in diastolic tension or relaxation parameters were detected (data not shown). Overall, GLP-1(7-36) amide and exenatide had similar functional effects in atrial tissue.

\section{The Impact of GLP-1(9-36) Amide on Atrial Tissue}

Besides the two GLP1 receptor agonists, muscle strips superfused with either glucose or pyruvate enriched solution were treated with a single high dose of GLP$1(9-36)$ amide (200 $\mathrm{nM})$, which is an antagonist of the GLP1 receptor. Figure 3 shows the functional effects on either glucose-treated (filled squares; $n=13$ trabeculae) or pyruvatetreated (open circles; $\mathrm{n}=13$ trabeculae) muscle strips. ${ }^{\# \#} \mathrm{p}<0.001$ between groups, $* * * * p<0.0001$ vs BL. b Analysis of developed force delta to baseline at time point of steady state conditions for glucose-treated (black bar) and pyruvate-treated (white bar) trabeculae. No statistical difference between groups $(p=0.052)$

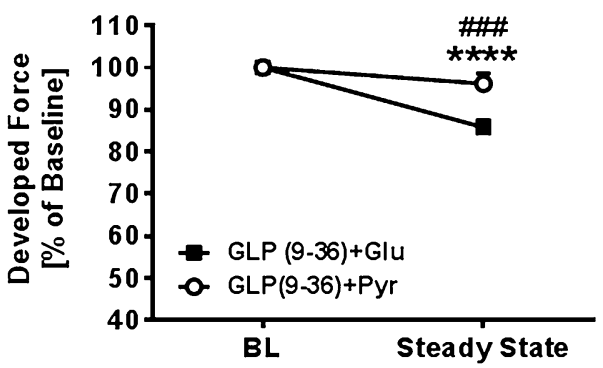

Fig. 3 GLP-1(9-36) amide has no effect on contractility of human atrial myocardium. In contrast to GLP-1 receptor agonists, the antagonist GLP-1(9-36) amide exerts no positive inotropic effect in the presence of either substrate. Data are represented as mean \pm SEM. A single dose of $200 \mathrm{nM}$ GLP-1(9-36) amide was administrated on either glucose-treated (filled squares; $n=6$ trabeculae) or pyruvate-treated (open circles; $n=6$ trabeculae) trabeculae. ${ }^{\# \# \#} \mathrm{p}<0.001$ between groups, $* * * * \mathrm{p}<0.0001$ vs BL (glucose-treated trabeculae) 
developed force $25 \mathrm{~min}$ after the intervention. In glucose treated muscle strips, the decrease in developed force after administration of GLP-1(9-36) amide was more pronounced $(85.7 \pm 1.7 \%$ of $\mathrm{BL})$ compared to muscle strips that were treated with pyruvate $(96.2 \pm 2.4 \%$ of BL; $\mathrm{p}=0.0001$ ). Similar to what was observed after administration of the GLP-1 receptor agonists to the muscle strips, administration of GLP-1(9-36) amide induced no change in diastolic tension or relaxation parameters (data not shown).

\section{Beta Receptor Activation in Atrial Tissue}

To further investigate the observed variations of the GLP-1 receptor dependent positive inotropic effect using different energy substrates, muscle strips superfused with either glucose or pyruvate enriched solution were treated with a single dose of $100 \mathrm{nM}$ isoproterenol, a beta receptor agonist. Figure 4 shows the increase in developed force between BL and steady state conditions 25 min after the intervention. Although the positive inotropic effect, expressed as the change in developed force, was stronger in the presence of glucose $(179.1 \pm 68.0 \%)$ compared to pyruvate $(121.8 \pm 32.9 \%)$, there was no statistical difference between the groups $(p=0.47)$. This suggests that beta receptor activation is followed by a similar inotropic response in the presence of each used energy substrate. No changes in relaxation parameters or diastolic tension could be detected (data not shown).

\section{Isoproterenol}

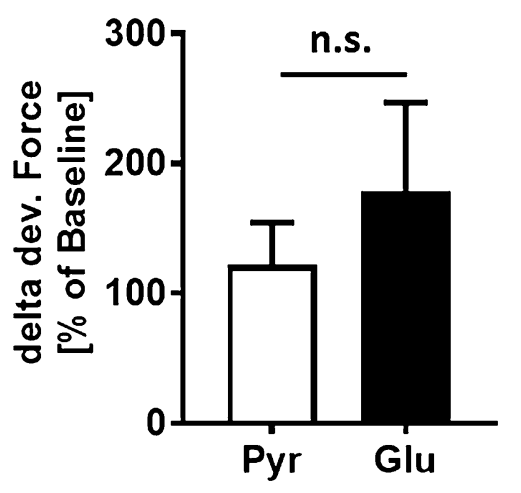

Fig. 4 Isoproterenol exerts similar positive inotropic effects in the presence of glucose or pyruvate in human atrial myocardium. In contrast to GLP-1 receptor agonists, beta receptor activation reveals similar effects in the presence of either substrate. Data are represented as mean \pm SEM. A single dose of $100 \mathrm{nM}$ isoproterenol was administrated on either glucose-treated (black bar; $n=6$ trabeculae) or pyruvate-treated (white bar; $n=6$ trabeculae) trabeculae. Analysis of developed force delta to baseline at time point of steady state conditions. No statistical difference between groups $(p=0.47)$

\section{Calcium Response in the Presence of Pyruvate and Glucose}

A stepwise increase in calcium concentrations led to a similar positive inotropic effect in the presence of glucose and pyruvate. As shown in Fig. 5, the effect was slightly more pronounced in the presence of glucose. However, no significant difference in comparison to pyruvate-treated muscle strips could be observed at the concentrations of $4.0 \mathrm{mM}$ calcium $(146.6 \pm 14.8 \%$ of $\mathrm{BL}$ in glucose versus $136.7 \pm 13.2 \%$ of BL in pyruvate) and $7.2 \mathrm{mM}$ calcium $(187.1 \pm 19.5 \%$ of BL in glucose versus $156.7 \pm 21.9 \%$ of $\mathrm{BL}$ in pyruvate; $\mathrm{p}=0.4$ between groups). This result suggests a comparable myocardial contractility in response to calcium in the presence of glucose or pyruvate. No changes in relaxation parameters or diastolic tension could be detected (data not shown).

\section{Discussion}

Our findings demonstrated that the GLP-1 receptor agonists exenatide and GLP-1(7-36) amide, but not the GLP-1 receptor antagonist GLP-1(9-36) amide, exerted positive inotropic effects in the presence of both glucose and pyruvate. This effect was more pronounced in the presence of glucose. However, beta receptor activation and increasing calcium concentrations were followed by a similar positive inotropic effect without significant differences between the energy substrates.

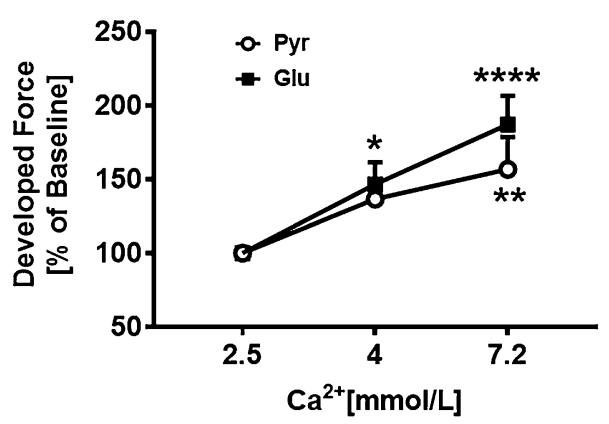

Fig. 5 Substrate-dependent inotropic response to calcium on human atrial myocardium. Elevated calcium concentrations lead to a positive inotropic effect in the presence of both substrates. Data are represented as mean \pm SEM. Calcium concentrations were elevated from 2.5 to $4.0 \mathrm{mM}$ and further to $7.2 \mathrm{mM}$ in either glucose-treated (filled squares; $\mathrm{n}=6$ trabeculae) or pyruvate-treated (open circles; $\mathrm{n}=7$ trabeculae) trabeculae. ${ }^{*} \mathrm{p}<0.05$ vs $\mathrm{BL}, * * \mathrm{p}<0.01$ vs $\mathrm{BL}$, $* * * * \mathrm{p}<0.0001$ vs $\mathrm{BL}$. No statistical difference between groups $(\mathrm{p}=0.4)$ 


\section{Translocation of GLUT1}

Glucose and pyruvate incubated muscle strips showed comparable patterns of positive inotropy: first, an acute phase with a significant increase in developed force was observed, which was followed by a decline until steady state was reached (about 25 min after drug administration). This is consistent with the findings of a previous report that demonstrated a transient positive inotropic effect, which is most likely the result of GLP-1 receptor desensitization. Furthermore, it was shown that incubation with $2 \mathrm{nM}$ exenatide for $3 \mathrm{~h}$ induced increased translocation of glucose transporter GLUT1 from the cytosol to the membrane in atrial cardiomyocytes (Wallner et al. 2015). So far, there is no data available regarding the downstream mechanism that induces the GLUT1 translocation after GLP-1 receptor activation. In the current experiments, steady state conditions were reached $25 \mathrm{~min}$ after adding the drugs. At this time point, glucose incubated muscle strips showed a stronger positive inotropic effect than pyruvate incubated muscle strips. This effect may be a consequence of improved glucose metabolism via enhanced translocation of GLUT1, with subsequent generation of more adenosine-3-phosphate (ATP). GLUT1 expression plays a major role in basal glucose uptake in the heart, however the most important glucose transporter for the adult heart is GLUT4 (Shao and Tian 2015). Pools of both GLUT1 and GLUT4 are located inside cardiomyocytes within compartments of endosomes and may be recruited if the appropriate signals reach these pools (Becker et al. 2001). Pathophysiological processes can lead to an upregulation of GLUT-1, which is observed in conditions of hypertrophy of the heart or chronic hypoxia/ischemia (Shao and Tian 2015; Szablewski 2017). However, in contrast to GLUT-4 translocation, the underlying mechanisms of the GLUT-1 translocation are poorly understood and interactions with the incretin system have yet to be studied more in depth. To be mentioned in this context, myocardial glucose uptake via translocation of GLUT4 amplifies the positive inotropic effect of insulin independent of calcium (Lewinski et al. 2010).

\section{Pyruvate and Glucose as Energy Substrates}

All pyruvate-treated muscle strips showed a much stronger basal contractility compared to those treated with glucose (data not shown). It may be possible that the observed weaker positive inotropic effect of GLP-1 receptor agonists in the presence of pyruvate is a consequence of a higher contractility at BL and a subsequent partial inotropic incompetence, while the glucose pretreated muscle strips could react properly to GLP-1 receptor activation. For pyruvate, positive inotropic abilities have been reported (Torres et al. 2013; Hasenfuss et al. 2002), which may also explain the results of the experiments performed with GLP-1(9-36) amide by counteracting the physiological rundown. The concentration of pyruvate used was twice as high as the concentration of glucose because one molecule of glucose is degraded into two molecules of pyruvate during glycolysis. The main part of the energy metabolism and synthesis of ATP takes place in the citrate cycle. However, the direct effect on contractility by pyruvate was underestimated. The small positive inotropic effect observed after GLP-1(7-36) amide administration to the pyruvate-treated muscle strips is also a consequence of a rather high number of non-responders with no adequate explanation so far.

Pyruvate and glucose treated muscle strips showed a similar response to beta receptor activation in contrast to GLP-1 receptor activation. This implicates a comparable inotropic competence is preserved in response to downstream targets of the protein kinase A. In line with this finding, increasing only the concentration of calcium caused a similar positive inotropic effect in the presence of glucose and pyruvate. The latter observation suggests a similar myocardial calcium metabolism. Given that calcium-regulatory proteins of cardiomyocytes are partly dependent on ATP availability (Fearnley et al. 2011), both energy substrates used may provide a comparable amount of ATP in atrial muscle strips and furthermore, the BL condition of the muscle strips is similar in the presence of glucose and pyruvate. The observed slightly stronger positive inotropic effects in the presence of glucose may still be caused by the difference in basal contractility.

\section{The Positive Inotropic Effect by GLP1r Agonists on Atrial Myocardium}

Left ventricular filling is the result of both left ventricular relaxation and left atrial contraction. The latter action takes place in late diastole and contributes up to $30 \%$ of left ventricular filling. Patients with T2DM are at an increased risk of left atrial dysfunction and chronic heart failure (Mondillo et al. 2011; Graca et al. 2014). In conditions of systolic and diastolic heart failure, backwards transmission of increased left ventricular end-diastolic filling pressures causes an enlargement and remodeling of the left atrium. This in turn strengthens the role of the left atrium in the process of left ventricular filling (Missiri and Awadalla 2016; Santos et al. 2016) and an increase in the contractility of the left atrium may be helpful in such conditions (Scherr et al. 2016). Given that improved atrial function is associated with beneficial outcomes in heart failure patients, preservation of atrial function may therefore be particularly important in patients with T2DM. In fact, decreased left atrial ejection fraction (LAEF) was associated with decreased left ventricular ejection fraction (LVEF), lower functional capacity, and higher rates 
of heart failure hospitalizations in patients with heart failure (Terzi et al. 2005; Kuhl et al. 2010). Also, in patients with coronary artery disease or myocardial infarction, left atrial dysfunction was an independent determinant of heart failure hospitalizations and mortality (Kuhl et al. 2011; Welles et al. 2012). As a consequence, atrial fibrillation, which is equal to a loss of atrial function, significantly increases the risk of mortality in both symptomatic and asymptomatic heart failure patients (Wang et al. 2003; Dries et al. 1998).

\section{Limitations of the Study}

One major limitation of the study is the fact that it only provides functional data and no mechanistic insights. The observed stronger positive inotropic effect of GLP-1 receptor agonists in the presence of glucose should be noted critically. A translocation of GLUT1 after exenatide administration was not shown and only assumed based on recently published data. In this context, experiments that show a translocation of GLUT1 after GLP-1(7-36) amide administration were never performed. Additionally, the importance regarding the difference in basal contractility of both energy substrates remains unclear.

The strength of the study is the use of human atrial tissue. Furthermore, myocardium was stimulated at a frequency of $1 \mathrm{~Hz}$ in bicarbonate buffered solutions, recapitulating physiological conditions within this in-vitro model. The functional inotropic properties of the GLP-1 receptor agonists exenatide and GLP-1(7-36) amide were assessed carefully and the results compliment previous findings of the interaction of GLP-1 receptor agonists on cardiac tissue. This is of particular interest because these drugs are already in clinical use as anti-diabetic therapeutics.

\section{Conclusion}

The administration of GLP1 receptor agonists leads to a positive inotropic effect in the presence of glucose and pyruvate. This effect is more pronounced in glucose enriched Tyrode's solution, suggesting substrate dependent inotropic differences after GLP-1 receptor activation, which might be linked to previously reported translocation of GLUT1.

Acknowledgements Open access funding provided by Medical University of Graz. We thank Friederike von Lewinski, MD, PhD for her contribution to the study design and planning.
Author Contributions DvL and EK: designed research; TK and ND: performed research; DvL, MW, KA, BP and PPR: analyzed data; EK, $\mathrm{NV}$, and DE: wrote the manuscript; MW: performed statistical analysis.

\section{Compliance with Ethical Standards}

Conflict of interest The authors declare that there is no conflict of interest regarding the publication of this paper.

Open Access This article is distributed under the terms of the Creative Commons Attribution 4.0 International License (http://creativeco mmons.org/licenses/by/4.0/), which permits unrestricted use, distribution, and reproduction in any medium, provided you give appropriate credit to the original author(s) and the source, provide a link to the Creative Commons license, and indicate if changes were made.

\section{References}

Baggio LL, Drucker DJ (2007) Biology of incretins: GLP-1 and GIP. Gastroenterology 132(6):2131-2157

Bailey CJ, Aschner P, Del Prato S, LaSalle J, Ji L, Matthaei S, Global Partnership for Effective Diabetes Management (2013) Individualized glycaemic targets and pharmacotherapy in type 2 diabetes. Diab Vasc Dis Res 10(5):397-409

Becker C, Sevilla L, Tomas E, Palacin M, Zorzano A, Fischer Y (2001) The endosomal compartment is an insulin-sensitive recruitment site for GLUT4 and GLUT1 glucose transporters in cardiac myocytes. Endocrinology 142(12):5267-5276

Bruderer SG, Bodmer M, Jick SS, Bader G, Schlienger RG, Meier CR (2014) Incidence of and risk factors for severe hypoglycaemia in treated type 2 diabetes mellitus patients in the UK - a nested casecontrol analysis. Diabetes Obes Metab 16(9):801-811

Dries DL, Exner DV, Gersh BJ, Domanski MJ, Waclawiw MA, Stevenson LW (1998) Atrial fibrillation is associated with an increased risk for mortality and heart failure progression in patients with asymptomatic and symptomatic left ventricular systolic dysfunction: a retrospective analysis of the SOLVD trials. Studies of Left Ventricular Dysfunction. J Am Coll Cardiol 32(3):695-703

Drucker DJ, Nauck MA (2006) The incretin system: glucagon-like peptide-1 receptor agonists and dipeptidyl peptidase-4 inhibitors in type 2 diabetes. Lancet 368(9548):1696-1705

El Missiri A, Awadalla H (2016) Left atrial contractility in ischemic heart disease patients with left ventricular systolic dysfunction. J Cardiovasc Echogr 26(1):11-15

Fearnley CJ, Roderick HL, Bootman MD (2011) Calcium signaling in cardiac myocytes. Cold Spring Harb Perspect Biol 3(11):a004242

Graca B, Ferreira MJ, Donato P, Gomes L, Castelo-Branco M, CaseiroAlves F (2014) Left atrial dysfunction in type 2 diabetes mellitus: insights from cardiac MRI. Eur Radiol 24(11):2669-2676

Hasenfuss G, Maier LS, Hermann HP, Luers C, Hunlich M, Zeitz O, Janssen PM, Pieske B (2002) Influence of pyruvate on contractile performance and $\mathrm{Ca}(2+)$ cycling in isolated failing human myocardium. Circulation 105(2):194-199

Kuhl JT, Kofoed KF, Moller JE, Hammer-Hansen S, Kristensen T, Kober L, Kelbaek H (2010) Assessment of left atrial volume and mechanical function in ischemic heart disease: a multi slice computed tomography study. Int J Cardiol 145(2):197-202

Kuhl JT, Moller JE, Kristensen TS, Kelbaek H, Kofoed KF (2011) Left atrial function and mortality in patients with NSTEMI an MDCT study. JACC Cardiovasc Imaging 4(10):1080-1087

Mondillo S, Cameli M, Caputo ML, Lisi M, Palmerini E, Padeletti M, Ballo P (2011) Early detection of left atrial strain abnormalities by 
speckle-tracking in hypertensive and diabetic patients with normal left atrial size. J Am Soc Echocardiogr 24(8):898-908

Nolan CJ, Damm P, Prentki M (2011) Type 2 diabetes across generations: from pathophysiology to prevention and management. Lancet 378(9786):169-181

Qaseem A, Barry MJ, Humphrey LL, Forciea MA, Clinical Guidelines Committee of the American College of Physicians (2017) Oral pharmacologic treatment of type 2 diabetes mellitus: a clinical practice guideline update from the American College of Physicians. Ann Intern Med 166(4):279-290

Richards P, Parker HE, Adriaenssens AE, Hodgson JM, Cork SC, Trapp S, Gribble FM, Reimann F (2014) Identification and characterization of GLP-1 receptor-expressing cells using a new transgenic mouse model. Diabetes 63(4):1224-1233

Santos AB, Roca GQ, Claggett B, Sweitzer NK, Shah SJ, Anand IS, Fang JC, Zile MR, Pitt B, Solomon SD, Shah AM (2016) Prognostic relevance of left atrial dysfunction in heart failure with preserved ejection fraction. Circ Heart Fail 9(4):e002763

Scherr J, Jung P, Schuster T, Pollmer L, Eisele G, Goss F, Schneider J, Halle M (2016) Left ventricular diastolic function is strongly correlated with active emptying of the left atrium: a novel analysis using three-dimensional echocardiography. Cardiovasc Ultrasound 14(1):43

Shao D, Tian R (2015) Glucose transporters in cardiac metabolism and hypertrophy. Compr Physiol 6(1):331-351

Standl E, Schnell O, McGuire DK (2016) Heart failure considerations of antihyperglycemic medications for type 2 diabetes. Circ Res 118(11):1830-1843

Strang AC, van Wijk DF, Mutsaerts HJ, Stroes ES, Nederveen AJ, Rotmans JI, Rabelink TJ, Box FM (2015) Guideline treatment results in regression of atherosclerosis in type 2 diabetes mellitus. Diab Vasc Dis Res 12(2):126-132

Szablewski L (2017) Glucose transporters in healthy heart and in cardiac disease. Int J Cardiol 230:70-75

Terzi S, Dayi SU, Akbulut T, Sayar N, Bilsel T, Tangurek B, Akgoz H, Kose H, Yilmazer S, Yesilcimen K (2005) Value of left atrial function in predicting exercise capacity in heart failure with moderate to severe left ventricular systolic dysfunction. Int Heart J 46(1):123-131

Torres CA, Varian KD, Canan CH, Davis JP, Janssen PM (2013) The positive inotropic effect of pyruvate involves an increase in myofilament calcium sensitivity. PLoS ONE 8(5):e63608
Tschope D, Bramlage P, Schneider S, Gitt AK (2016) Incidence, characteristics and impact of hypoglycaemia in patients receiving intensified treatment for inadequately controlled type 2 diabetes mellitus. Diab Vasc Dis Res 13(1):2-12

Vaidya V, Gangan N, Sheehan J (2015) Impact of cardiovascular complications among patients with type 2 diabetes mellitus: a systematic review. Expert Rev Pharmacoecon Outcomes Res 15(3):487-497

von Lewinski D, Bisping E, Elgner A, Kockskamper J, Pieske B (2007) Mechanistic insight into the functional and toxic effects of Strophanthidin in the failing human myocardium. Eur J Heart Fail 9(11):1086-1094

von Lewinski D, Gasser R, Rainer PP, Huber MS, Wilhelm B, Roessl U, Haas T, Wasler A, Grimm M, Bisping E, Pieske B (2010) Functional effects of glucose transporters in human ventricular myocardium. Eur J Heart Fail 12(2):106-113

Wallner M, Kolesnik E, Ablasser K, Khafaga M, Wakula P, Ljubojevic S, Thon-Gutschi EM, Sourij H, Kapl M, Edmunds NJ, Kuzmiski JB, Griffith DA, Knez I, Pieske B, von Lewinski D (2015) Exenatide exerts a PKA-dependent positive inotropic effect in human atrial myocardium: GLP-1R mediated effects in human myocardium. J Mol Cell Cardiol 89(Pt B):365-375

Wang TJ, Larson MG, Levy D, Vasan RS, Leip EP, Wolf PA, D'Agostino RB, Murabito JM, Kannel WB, Benjamin EJ (2003) Temporal relations of atrial fibrillation and congestive heart failure and their joint influence on mortality: the Framingham Heart Study. Circulation 107(23):2920-2925

Welles CC, Ku IA, Kwan DM, Whooley MA, Schiller NB, Turakhia MP (2012) Left atrial function predicts heart failure hospitalization in subjects with preserved ejection fraction and coronary heart disease: longitudinal data from the Heart and Soul Study. J Am Coll Cardiol 59(7):673-680

Zoungas S, Patel A, Chalmers J, de Galan BE, Li Q, Billot L, Woodward M, Ninomiya T, Neal B, MacMahon S, Grobbee DE, Kengne AP, Marre M, Heller S, ADVANCE Collaborative Group (2010) Severe hypoglycemia and risks of vascular events and death. N Engl J Med 363(15):1410-1418 